\title{
ABACADABRA: DESENVOLVIMENTO DE UM CONJUNTO EDUCATIVO PARA CRIANÇAS COM AUTISMO
}

\section{ABACADABRA: DEVELOPMENT OF AN EDUCATION SET FOR CHILDREN WITH AUTISM}

\author{
Daniele de Melo Silvano ${ }^{1}$, Tecn. \\ Gizely Cesconetto de Campos², Me. \\ Valeska Bernardo Rangel ${ }^{3}$, Dra. \\ (1) Instituto Federal de Educação Ciência, e Tecnologia de Santa Catarina (IFSC) \\ danielems.aha@gmail.com \\ (2) Instituto Federal de Educação Ciência, e Tecnologia de Santa Catarina (IFSC) \\ gizely11sr@gmail.com \\ (3) Instituto Federal de Educação Ciência, e Tecnologia de Santa Catarina (IFSC) \\ valeskabr@gmail.com
}

crianças com autismo, comunicação alternativa, projeto de produto

Este artigo descreve os resultados de um trabalho de conclusão do curso Design de Produto no Instituto Federal de Santa Catarina, cujo objetivo central foi desenvolver um conjunto educativo para auxiliar na intervenção de crianças com autismo. Conforme a pesquisa informacional, observação de campo e análise comparativa dos produtos, identificou-se a necessidade de aplicar melhorias na usabilidade de um sistema de comunicação alternativa por intermédio de figuras. Com isso, esse projeto partiu da inspiração no estilo Flat Design para reformular a interface do referido sistema, gerando uma proposta diferenciada que ajuda no aprendizado da rotina diária em crianças com autismo. Para amparar a execução do trabalho, foram empregadas metodologias de projeto de produto e pesquisa científica, com a realização de uma parceria com o CAD em São Carlos/SP, um espaço multidisciplinar que oferece às crianças um atendimento individual baseado na Análise de Comportamento Aplicada (ABA).

children with autism, alternative communication, product design

This paper describes the results of a monograph of the Product Design course held at the Federal Institute of Santa Catarina, whose main goal was to develop an educational set to assist in the intervention of children with autism. Due to the information research, field observation, and comparative product analysis, we identified that it is needed to apply improvements in the usability of a picture exchange communication system. Thus, this project started from the inspiration in the Flat Design style to redesign the interface of the system, creating a new proposal that helps in the learning of daily routine in children with autism. To support the execution of this work, we employed design and scientific research methodologies together with a partnership with the CAD in São Carlos / SP, which is a nonprofit organization that offers to children an individual care based on Applied Behavior Analysis (ABA). 


\section{$16^{\circ}$ \\ ERGODESIGN USIHC CINAHPA}

\section{Introdução}

De acordo com a perspectiva histórico cultural, a linguagem desempenha um papel fundamental no desenvolvimento infantil, pois ela permite que a criança constitua seus próprios significados na medida em que convive com outros membros mais experientes, favorecendo a aprendizagem e socialização (VYGOTSKY, 2005). Contudo, algumas crianças que se comunicam de maneira peculiar encontram dificuldades para dominar funcionalmente uma linguagem verbal, assim recorrendo ao uso complementar de sistemas de comunicação alternativa. Com isso, torna-se mais trabalhoso compreender o propósito prático de algumas tarefas da rotina diária, e assim aplicá-las por iniciativa própria. Dentre esta população especial, encontram-se as crianças diagnosticadas com Transtorno do Espectro Autista (TEA).

Em geral os comprometimentos mais reconhecidos podem ser observados no desenvolvimento atípico da comunicação e interação social, com a presença de um repertório de atividades e interesses restrito e estereotipado (BOSA, 2006). Entretanto, não há uma resposta única para definir as causas, diagnosticar e classificar o autismo, posto que o espectro abrange uma diversidade de comportamentos com gravidades distintas. Nesse sentido, a escolha de uma intervenção não é genérica, pois cada criança deve receber um atendimento compatível com seu nível de desenvolvimento e que considere suas características individuais a longo prazo (BOSA, 2002).

Estimativas apontam um aumento da frequência de casos de autismo nos últimos anos, atingindo uma prevalência tão alta quanto 1 em cada 68 crianças diagnosticadas (CHRISTENSEN et al, 2016). Esse aumento pode ser justificado pela expansão dos critérios diagnósticos e o melhoramento de alguns dos serviços de atendimento, através de campanhas informativas e orientações especializadas.

Dentro desse contexto, Lovaas (2003) sugere que apenas 5 a cada 100 crianças diagnosticadas são "capazes" de viver fora de instituições sem $16^{\circ}$ Ergodesign - Congresso Internacional de Ergonomia e Usabilidade de Interfaces Humano Tecnológica: Produto, Informações Ambientes Construídos e Transporte

$16^{\circ}$ USIHC - Congresso Internacional de Ergonomia e Usabilidade de Interfaces Humano Computador

CINAHPA | 2017 - Congresso Internacional de Ambientes Hipermídia para Aprendizagem. cuidado integral, assim evidenciando a necessidade constante de trabalhar na conscientização da população em geral sobre as formas de intervenção existentes. Considerando a proposta de um produto para auxiliar na rotina diária, esse projeto manteve como uma de suas motivações proporcionar uma oportunidade de autonomia para criança com autismo.

Apesar desse cenário, há um consenso sobre os benefícios da intervenção comportamental precoce. A Análise do Comportamento Aplicada (ABA) é amplamente difundida, com resultados efetivos e melhorias duradouras que favorecem a descaracterização do autismo nas crianças, desenvolvendo as áreas afetadas (LOVAAS, 2003). A intervenção ABA é intensiva, diretiva e dirigida, pois considera o repertório de cada criança para trabalhar na transformação de comportamentos problemáticos e no ensino de novas habilidades (MIGUEL; KENYON, 2005).

A partir disso, foi realizada uma parceria com o Centro de Aprendizagem e Desenvolvimento (CAD) em São Carlos/SP, cujo foco de trabalho incide sobre este programa de intervenção. Esse espaço de trabalho multidisciplinar, proporcionou entendimento prático da problemática geral do trabalho e da abordagem de intervenção escolhida. Através desse referencial empírico, foi possível realizar pesquisas qualitativas que contribuíram para o desenvolvimento projetual.

Com base na conjectura de que por meio da linguagem a criança constrói sua identidade, suas relações com o outro e com o contexto sociocultural, foi formulado o seguinte problema: Quais são as possíveis diretrizes para um projeto de produto que compreenda os aspectos do desenvolvimento da criança autista, direcionando elementos expressivos da sua personalidade para viabilizar sua comunicação, aprendizagem e autonomia?

Neste artigo será enfatizado apenas os resultados do presente trabalho, com uma breve abordagem da revisão teórica para auxiliar no entendimento da proposta do produto. Informações mais detalhadas podem ser consultadas em Silvano (2016).

Realização:




\section{$16^{\circ}$ \\ ERGODESIGN USIHC CINAHPA}

$16^{\circ}$ Ergodesign - Congresso Internacional de Ergonomia e Usabilidade de Interfaces Humano Tecnológica: Produto, Informações Ambientes Construídos e Transporte

$16^{\circ}$ USIHC - Congresso Internacional de Ergonomia e Usabilidade de Interfaces Humano Computador

CINAHPA | 2017 - Congresso Internacional de Ambientes Hipermídia para Aprendizagem.

\section{Metodologia}

A estrutura do método PDP (Figura 1) proposto em Rozenfeld et al. (2006) foi adaptada para se adequar ao formato e prazos lineares previamente estipulados para este trabalho, sendo complementada por ferramentas específicas de acordo com as exigências de cada etapa.

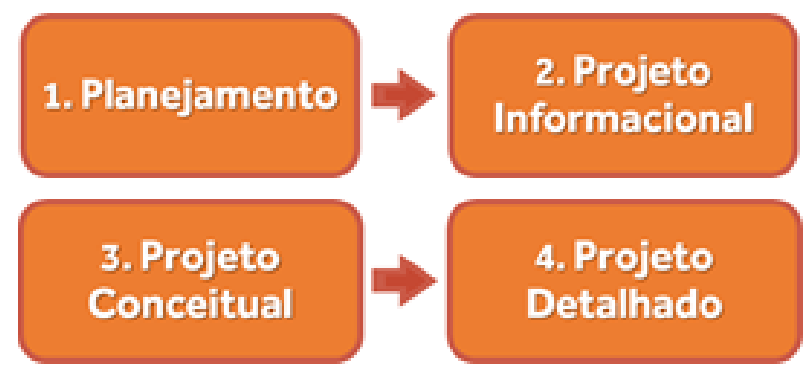

Figura 1 - Método adaptado de Rozenfeld et al., 2006.

A etapa de Planejamento estabeleceu direcionamentos para o projeto a partir de uma pesquisa e visita preliminar ao $\mathrm{CAD}$, associação que atende as crianças com autismo. O Projeto Informacional incluiu uma revisão sistemática dos principais conceitos abordados no trabalho de acordo com as ênfases em três níveis descritos por Gil (2006): exploratório, analítico e interpretativo. A perspectiva histórico cultural presente em Vygotsky (2005) orientou o desenvolvimento teórico do trabalho, estudando as principais categorias conceituais atreladas ao desenvolvimento infantil, enquanto os aspectos específicos relacionados ao autismo foram estudados sob a perspectiva da ABA em função da sua abrangência e interdisciplinaridade (LOVAAS, 2003).

Na segunda parte do Projeto Informacional, visando levantar os principais problemas da interação do usuário com o produto foram realizadas observações assistemáticas e análises de tarefa (BAXTER, 2011), com o consentimento e orientação dos responsáveis e colaboradores do CAD. Nesta etapa também foi efetuada uma análise comparativa de produtos similares, incluindo uma pesquisa imagética compilada na forma de painéis semântico de estilo visual e expressão do produto as quais auxiliam na concepção do projeto. Para isso, foram considerados o acervo de brinquedos educativos e literatura infantil utilizados no CAD e na Brinquedoteca de Educação Especial da UFSCar, assim como os seus similares nas redes de distribuição local. Posteriormente, realizou-se um estudo dos principais sistemas de comunicação alternativa e aumentativa utilizados no desenvolvimento da linguagem em crianças com autismo. A partir das informações obtidas, no final desta etapa foram definidas as diretrizes para o projeto de produto em torno de critérios como usabilidade, estética e segurança.

Para auxiliar no Projeto Conceitual foram adaptadas algumas ferramentas de criatividade presentes na literatura de Baxter (2011): (a) Brainstorming, ou "sessão de agitação de ideias"; (b) Analogias consiste em transferir propriedades de um objeto para outro diferente considerando relações como proximidade, semelhança, contraste; (c) Análise paramétrica "serve para comparar produtos em desenvolvimento com produtos já existentes baseando-se em variáveis chamadas de parâmetros comparativos" (ibid. p.72).

O Projeto Detalhado especificou o produto a nível de produção efetiva, por isso após um refinamento conceitual com base no estilo Flat Design ${ }^{1}$, foi definido as especificações técnicas para prototipação e validação ergonômica. Para representar a realidade pretendida, também foram utilizados recursos de apoio visual como ilustrações manuais, renderizações digitais, e material multimídia (GOMES FILHO, 2006).

\section{Comunicação Alternativa e Aumentativa}

De acordo com Manzini e Deliberato (2004), é comum a associação entre o conceito de comunicação e linguagem verbal, já que através da fala expressa-se emoções e articula-se ideias. Entretanto, o processo de comunicação revela-se complexo e vai além do que pode ser manifestado através da fala, sendo que, diversos recursos são

1 O Design Plano é uma tendência contemporânea presente no Design de Interfaces (SÁ, 2014), orientada por uma abordagem funcionalista e responsiva com a simplificação da interface gráfica focada na usabilidade.
Realização:

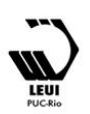




\section{$16^{\circ}$ \\ ERGODESIGN USIHC CINAHPA}

empregados durante a interação social, misturandose e complementando-se como a linguagem gestual, corporal, aumentativa e alternativa.

Algumas crianças com autismo podem sentir dificuldade em aderir a uma linguagem comum, tal como a verbal, pois não atribuem um propósito prático na tarefa de se comunicar adequadamente, e porque comunicar-se por meio dessas linguagens requer a compreensão e memorização de combinações extensas de componentes linguísticos. Desta forma, surgem adversidades no campo da percepção, seleção e processamento adequado de informações para responder aos estímulos do ambiente.

Considerando isso, os sistemas de comunicação alternativa e aumentativa são empregados para complementar a fala e contribuir para que ocorra a comunicação efetiva. Sendo amplamente difundidos na rotina diária das crianças não verbais ou com dificuldades na fala, eles contribuem para transformação do pensamento concreto em abstrato, próprio das linguagens em suas diversas esferas. Ao facilitar que a comunicação funcional ocorra, mostra-se que a linguagem é o caminho mais apropriado para atingir consequências modificadoras e desejáveis, assim evitando a recorrência de comportamentos problemáticos que possam interferir no aprendizado, como a autolesão ou ecolalia (BOSA, 2006).

O Picture Exchange Communication System (PECS) ou, Sistema de Comunicação por Troca de Figuras, consiste em um método de ensino por intermédio de pictogramas ou símbolos gráficos. Nele, conforme os níveis aplicação, a criança (locutor) pode entregar ou sinalizar para outra pessoa (sua interlocutora) a figura referente ao seu pedido, ou retirar a figura da prancha e encaixar sobre uma tira de sentença elaborando um pedido mais complexo. O material utilizado inclui basicamente, uma prancha de comunicação no formato A4, uma tira de sentença e cartões de papel com velcro contendo figuras que representam ações, objetos ou situações que a criança gostaria de expressar (MIGUEL; BRAGAKENYON; KENYON, 2005b). $16^{\circ}$ Ergodesign - Congresso Internacional de Ergonomia e Usabilidade de Interfaces Humano Tecnológica: Produto, Informações Ambientes Construídos e Transporte

$16^{\circ}$ USIHC - Congresso Internacional de Ergonomia e Usabilidade de Interfaces Humano Computador

CINAHPA | 2017 - Congresso Internacional de Ambientes Hipermídia para Aprendizagem.
A difusão oficial desse sistema é inviabilizada devido ao elevado custo de aquisição e treinamento, incluindo o pacote de figuras que retém os direitos autorais no país. Nesse caso, os pais e profissionais recorrem às adaptações manuais das pranchas e cartões (Figura 2), decorrendo em algumas interferências na usabilidade do sistema (SILVANO, 2016).

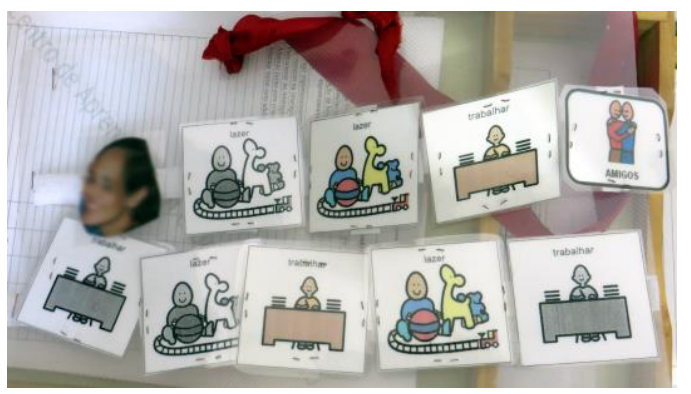

Figura 2 - Prancha de comunicação adaptada no CAD. Fonte: Acervo próprio, 2016.

Para compensar o tempo empreendido na confecção manual, as imagens são extraídas arbitrariamente de um banco de imagens, e agrupadas sem preocupação em relação à composição visual das pranchas. Nesse caso, a fragmentação fica evidente com a falta de contrastes claros e uma ordenação formal desarticulada (GOMES FILHO, 2009).

Os símbolos gráficos empregados nos cartões de comunicação (Figura 3) possuem um aspecto extremamente simples e icônico, com vistas e cores chapadas que prejudicam o entendimento da atividade representada. Durante as visitas no CAD, percebeu-se que as crianças apresentaram dificuldade para compreender os pictogramas no sentido de transpor a imagem para uma situação cotidiana, isso pois o seu pensamento é predominantemente concreto.

Parte desse impedimento pode ser explicado pelo desrespeito às técnicas de composição visual, mencionadas por Dondis (2007) tal como contraste, harmonia e fragmentação. A ausência da pregnância da forma, pode ser notada pela combinação desarmônica de geometrias com uma transição pouco suave entre diferentes elementos e sem continuidade que acaba por atrapalhar a sua rápida identificação.
Realização:

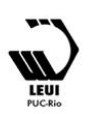




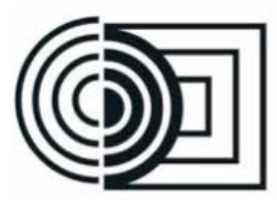

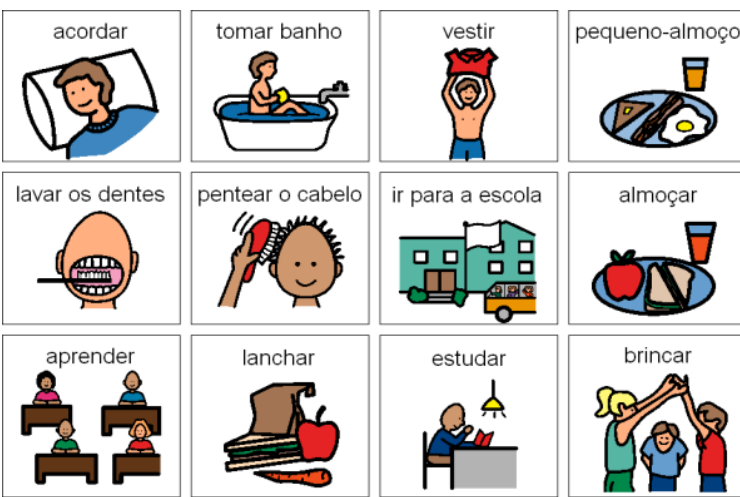

Figura 3 - Exemplo de prancha de comunicação. Fonte: Acervo do CAD, 2016.

Como constatado na pesquisa de campo, as instruções devem ser evidentes para que o autista possa se situar na ação. Um pictograma que representa a ação de comer ou escovar os dentes, podem ser confundidos entre si devido à semelhança do utensílio manuseado, e porque não apresentam uma sequência clara da tarefa que permita associar (generalizar) a situação

vivenciada anteriormente pela criança.

Portanto, é possível concluir que, esses símbolos gráficos não dialogam com a linguagem visual do universo infantil verificada na pesquisa dos brinquedos existentes (SILVANO, 2016). Com uma interface monótona, as dicas visuais são sutis com poucos indicativos de uso ou affordances ${ }^{2}$, prejudicando a capacitação do sistema.

Considerando o exposto, aponta-se a necessidade de uma reformulação de maneira a contemplar as características peculiares da infância e do espectro autista. Assim sendo, como elucida Löbach (2001), as preferências estéticas do usuário devem ser fatores direcionadores indispensáveis à configuração do produto, já que assumem uma função básica e determinante na sua usabilidade.

Exposto isso, a proposta de redesign dessas interfaces agregando esses novos elementos revela-

\footnotetext{
2 Para Norman (2006), affordances, determinados por princípios culturais e cognitivos, referem-se às propriedades fundamentais percebidas e reais de um objeto que sugerem a maneira que poderia ser utilizado, assim dispensando o uso de instruções. Por exemplo: maçanetas para girar, botão para apertar.
}

$16^{\circ}$ Ergodesign - Congresso Internacional de Ergonomia e Usabilidade de Interfaces Humano Tecnológica: Produto, Informações Ambientes Construídos e Transporte

$16^{\circ}$ USIHC - Congresso Internacional de Ergonomia e Usabilidade de Interfaces Humano Computador

CINAHPA | 2017 - Congresso Internacional de Ambientes Hipermídia para Aprendizagem.

se cada vez mais importante. Pois, como acrescenta Löbach (2001), esse processo de reformulação é necessário para incorporar novas técnicas, eliminar falhas existentes e melhorar a aparência estética do produto. O redesign pode surgir quando há mudanças nos requisitos do usuário e suas preferências formais, assim como a descoberta de novos materiais, processos ou modos de uso. Diante disso, deve-se adequar a proposta dos produtos, tal como a do sistema PECS, para se alinhar as novas necessidades emergentes observadas durante este trabalho, e assim contribuir para o propósito inicial de inclusão social e autonomia da criança.

\section{Conjunto Educativo "ABAcadabra!"}

"ABAcadabra!" é um conjunto educativo (Figura 4) para auxiliar no aprendizado de rotinas diárias em crianças com autismo. Com ele, é possível que os pais, e colaboradores, elaborem a rotina em conjunto com a criança, estruturando, nomeando e modificando as atividades conforme a necessidade de cada uma. Para este fim, foi desenvolvido um livro interativo contendo fichas magnéticas, com ilustrações de ações e cenários do cotidiano da criança, que podem ser combinadas de diferentes formas para compor uma sequência de atividades cotidianas. Para complementar esse quadro de rotinas, também foi elaborado um livro com instruções de higiene pessoal, referente a atividades em que a criança mais encontra dificuldade em memorizar a sequência.

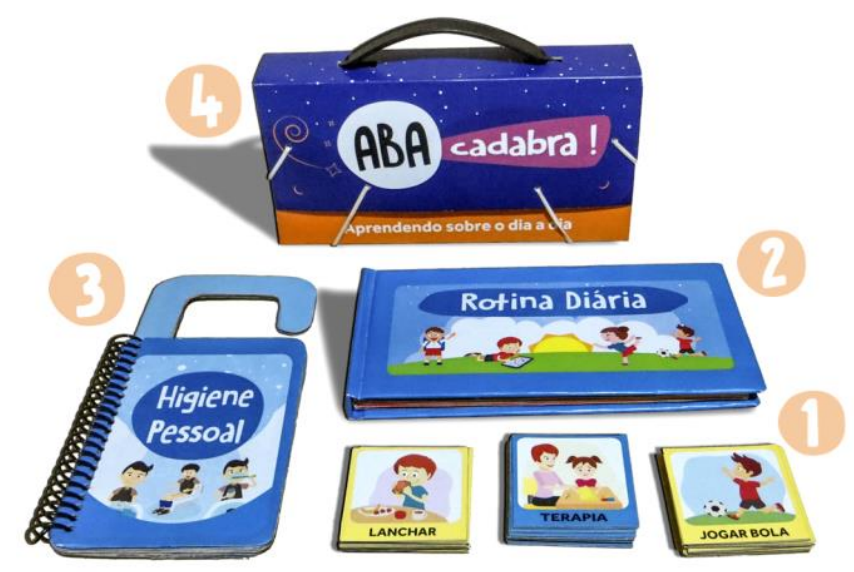

Figura 4 - Protótipo do Conjunto ABAcadabra!
Realização:
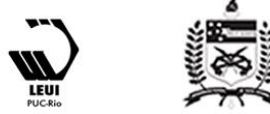


\section{$16^{\circ}$ \\ ERGODESIGN USIHC CINAHPA}

O nome "ABAcadabra!" foi inspirado na abordagem de intervenção considerada referência para a fundamentação teórica, sendo trabalhada também com as crianças no CAD, a Análise do Comportamento Aplicada (ABA). A partir disso, mesclou-se a expressão “cadabra!", que embora não exista uma tradução assertiva, está presente em diversos filmes infantis para referir-se a atos de mágica. Com isso, seguindo a motivação central que orientou o desenvolvimento deste trabalho, pretende-se agregar uma experiência lúdica dentro do contexto técnico das intervenções em crianças com autismo.

Para este projeto, buscou-se referências em um estilo que fosse de fácil assimilação pela criança seguindo as recomendações da intervenção ABA. Nas interfaces no estilo Flat Design observa-se a clareza no layout e a redução de elementos visuais como gradientes, bordas, sombras, ou qualquer outro que possa causar interferência visual. As cores e tipografias são sólidas, sem a utilização de efeitos de profundidade e detalhes serifados (SÁ, 2014).

Algumas técnicas visuais podem servir de fundamento para este estilo, tal como os pressupostos da psicologia da Gestalt, entre eles, a Proximidade e Semelhança, onde formas que estão próximas tendem a se agruparem constituindo uma unidade, pois quanto menor a distância entre elas maior é a unificação; e o Contraste, aplicado em cores e formas para destacar informações dentro de uma composição respeitando as regras de harmonia (DONDIS, 2007).

O processo de mapeamento e seleção dos pictogramas para efetuar o redesign da interface gráfica, partiu do estudo das figuras utilizadas no CAD pelas crianças, e da adaptação de alguns vetores no estilo Flat Design no Freepik, um banco de imagens gratuito.

Da soma de 50 pictogramas (Item 1) contidos no conjunto, 12 são cópias, visto que algumas atividades são recorrentes durante o quadro de rotina diária, por exemplo: as refeições em uma dieta balanceada devem ocorrer cerca de cinco vezes por dia para não ultrapassar o período de 3 horas; a intervenção $\mathrm{ABA}$ é recomendada duas $16^{\circ}$ Ergodesign - Congresso Internacional de Ergonomia e Usabilidade de Interfaces Humano Tecnológica: Produto, Informações Ambientes Construídos e Transporte

$16^{\circ}$ USIHC - Congresso Internacional de Ergonomia e Usabilidade de Interfaces Humano Computador

CINAHPA | 2017 - Congresso Internacional de Ambientes Hipermídia para Aprendizagem. vezes por dia para compor o quadro semanal de 20 horas; as atividades de higiene pessoal são cautelares ao longo de todo dia.

Para evitar a fragmentação observada nos pictogramas convencionais, o enquadramento das cenas teve como princípio a decomposição dos elementos considerados indispensáveis para a assimilação das ações e cenários representados. Por isso, alguns pictogramas enfatizaram ações (Figura 5), para viabilizar o seu rápido entendimento a longa distância, enquanto que outros enquadraram a cena integralmente. Por exemplo, na Terapia ABA as tarefas de mesinha são marcantes para a criança pois a maior parte dos programas são trabalhados nessa plataforma; ao tocar um instrumento musical como o violão, o foco é nos membros superiores, e assim por diante. Por outro lado, em ações como dançar, jogar bola e trocar, todo o corpo é envolvido no processo. Esse princípio pode ser explicado também pela Gestalt do Objeto, uma vez que quando elementos semelhantes estão próximos com uma transição suave, eles tendem a se unir constituindo um único cenário (GOMES FILHO, 2009), evitando dessa forma um ruído no agrupamento.

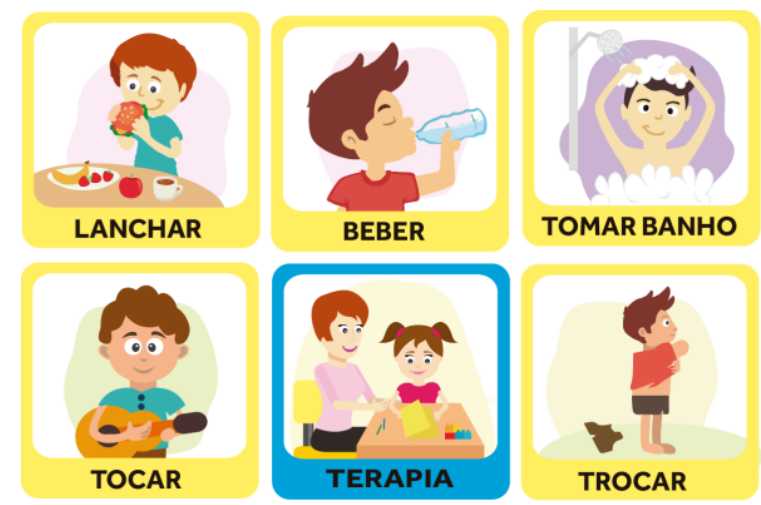

Figura 5 - Enquadramento das cenas

Os cenários dos pictogramas são classificados de acordo com a cor do fundo e com os personagens para cada contexto. Seguindo recomendação dos profissionais, os títulos dos pictogramas foram aplicados em negrito e em caixa alta, com uma moldura no fundo para proporcionar destaque e orientação ao sentido da leitura escrita e visual. A cor de moldura identifica o grupo correspondente para facilitar o seu agrupamento e diferenciação
Realização:

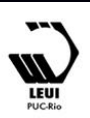




\section{$16^{\circ}$ \\ ERGODESIGN USIHC CINAHPA}

pela criança, sendo atribuída a cor amarela para ações e azul para lugares ou cenários específicos. Já a disposição em letras maiúsculas é muito presente na literatura infantil, pois facilita a assimilação pela criança em fase de alfabetização.

O livro interativo do conjunto (Item 2) é composto por 10 páginas, com um layout de distribuição de 6 pictogramas por página, atendendo as recomendações das fases iniciais de capacitação dos sistemas por troca de figuras, onde é empregado no máximo oito figuras ao longo de todo dia para não confundir a criança (SUCHOWIERSKA; RUPIŃSKA; BONDY, 2013).

Além disso, no plano de fundo das páginas (Figura 6), foram utilizados quadrados opacos com cantos arredondados, contendo os algarismos que indicam a sequência da atividade, e fornecem para a criança a dica visual para encaixe das fichas. As cores temáticas das páginas seguem a progressão do círculo cromático, com a ascendência de cores frias a cores quentes que identificam cada período do dia. Foram desenvolvidos também padrões de superfície gráfica a partir da decomposição de elementos do cotidiano infantil, dando assistência ao delineamento e distinção dos períodos.

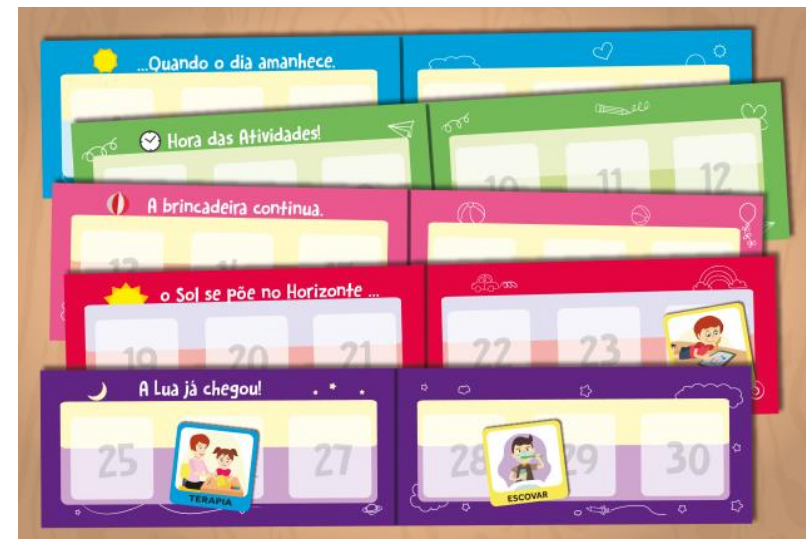

Figura 6 - Ambientação das páginas do livro

O livro de higiene pessoal (Item 3), possui esse formato pois é voltado para consulta rápida, podendo ser pendurado em portas de cômodos, armários entre outros locais de fácil acesso pela criança. As ilustrações do passo a passo das atividades de higiene pessoal foram elaboradas $16^{\circ}$ Ergodesign - Congresso Internacional de Ergonomia e Usabilidade de Interfaces Humano Tecnológica: Produto, Informações Ambientes Construídos e Transporte

$16^{\circ}$ USIHC - Congresso Internacional de Ergonomia e Usabilidade de Interfaces Humano Computador

CINAHPA | 2017 - Congresso Internacional de Ambientes Hipermídia para Aprendizagem.

com base no gênero masculino, tendo em vista que a prevalência dos casos de autismo é mais alta em meninos do que meninas seguindo uma proporção de 5 para 1 (CHRISTENSEN et al, 2016). As sequências das ilustrações foram estruturadas a partir do procedimento de trabalhar a rotina na intervenção ABA (FAGGIANI, 2011), no qual são detalhadas algumas atividades relatadas com maior dificuldade pela criança, tal como: Ir ao banheiro, lavar as mãos (Figura 7) e escovar os dentes.
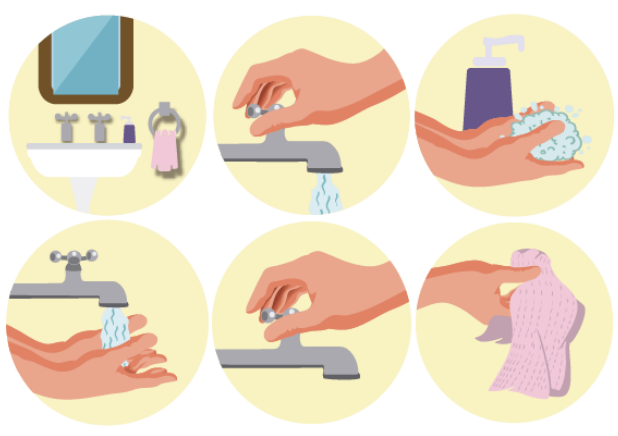

Figura 7 - Sequência ilustrada de lavar as mãos

A escolha da cor do tema principal se deu devido a sua aproximação com alguns conceitos pretendidos para esta proposta, tal como a higiene e limpeza. Em vista da cor azul ser fria e inerte (PEDROSA, 2004), ela não provoca um contraste dissonante com o restante da composição informacional o qual requer atenção da criança, como fica evidente em outras composições cromáticas que foram experimentadas. Além disso, azul é a cor oficial no Dia Mundial de Conscientização do Autismo, em 2 de abril, pois visa alertar sobre a prevalência dos casos de autismo em meninos.

A embalagem (Item 4) organiza, armazena e transporta os componentes do conjunto. Diferente da proposta com ênfase técnica observada na utilização de fichários no PECS, as dimensões desta embalagem são apropriadas para uma criança, tornando a experiência mais lúdica e confortável. Para facilitar o transporte, a embalagem possui uma alça superior semelhante as maletas de brinquedos infantis. $\mathrm{O}$ fechamento das abas ocorre por meio de uma alça elástica, garantindo praticidade e segurança ao abrir e fechar a embalagem. 


\section{$16^{\circ}$ \\ ERGODESIGN USIHC CINAHPA}

Para proporcionar um equilíbrio na composição das cores da identidade visual do conjunto, optouse pela cor violeta pois mescla tons de magenta e ciano, enquanto a cor laranja é a sua complementar, pois está no lado oposto do círculo cromático, constituindo uma composição harmônica (PEDROSA, 2004). Foram aplicados os mesmos padrões de fundo presentes nas páginas do livro interativo, conferindo identidade e harmonia ao conjunto. Na face interna da aba de encaixe, foi empregado o símbolo do quebra cabeça que expressa a complexidade e representa o Dia da Conscientização do Autismo.

É importante elucidar que a matéria prima de todo conjunto é o papel, pois oferece a vantagem do custo e peso reduzido, se adequando a diferentes aplicações e processos produtivos (GOMES FILHO, 2006). Esse material foi estrategicamente aplicado para corresponder as exigências do projeto, com gramaturas e acabamentos distintos para cada componente do conjunto. Assim como a combinação com folhas imantadas para manter a propriedade de junção, conforme descrito em Silvano (2016).

\section{Análise e Discussão dos Resultados}

Ao longo de todo processo buscou-se os aspectos do desenvolvimento da criança mostrando a importância da expressão e reconhecimento de sua singularidade. As atividades lúdicas também foram focadas através de propostas que trabalharam cores e formas atrativas, e o foco na autossuficiência, buscando agregar conteúdo educativo que vai além das técnicas convencionais de intervenção.

Com isso ficou evidente que a assistência de técnicas visuais contribui para organização das informações e o entendimento de sequencialidade para a criança, uma vez que expõe de modo panorâmico a sequência linear do passo a passo das atividades. Isso, pois, a dificuldade no processamento de informações em crianças com autismo está mais relacionada ao canal áudio vocal do que visual e motor (NUNES, 2001), assim busca-se explorar as suas potencialidades ao invés de ater-se somente as suas dificuldades. $16^{\circ}$ Ergodesign - Congresso Internacional de Ergonomia e Usabilidade de Interfaces Humano Tecnológica: Produto, Informações Ambientes Construídos e Transporte

$16^{\circ}$ USIHC - Congresso Internacional de Ergonomia e Usabilidade de Interfaces Humano Computador

CINAHPA | 2017 - Congresso Internacional de Ambientes Hipermídia para Aprendizagem.
Dentro do prazo estipulado para este trabalho não foi possível realizar a validação dos resultados em conjunto com as crianças no CAD. Em vista da amplitude do espectro autista, os procedimentos para estudo tornam-se intensivos, como elucidado por Nunes (2001), podendo levar de 6 a 8 meses para realizar a capacitação ou habilitação da criança para o uso de novos sistemas de comunicação, para então a partir disso obter-se resultados significativos que permitam trabalhar no aprimoramento da proposta. Além disso, é preciso depreender também um período adicional para aproximação do projetista com a nova área de conhecimento visando corresponder às necessidades reais do usuário (BONSIEPE, 2011).

Exposto isso, os resultados foram inferidos a partir da fundamentação teórica e do contato com profissionais especializados, que repassaram o seu parecer sobre as implicações desta proposta. Também foi realizada uma análise ergonômica para verificar a adequação das dimensões do produto às medidas antropométricas, tendo como referência uma criança com 8 anos (Figura 8).

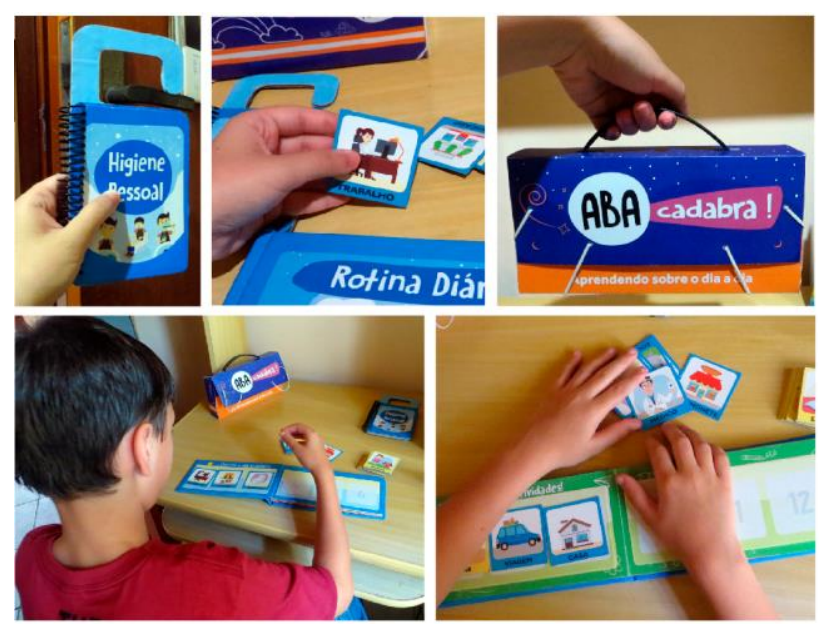

Figura 8 - Validação Ergonômica

Foram observados os dois tipos de manejos básicos, definidos por Iida (2003) como: fino ou preciso, aquele executado unicamente com as pontas dos dedos e que não envolve a palma da mão e o punho; e grosseiro ou de força, quando a pega envolve os braços, punho e palma da mão enquanto que os dedos servem para segurar. 


\section{$16^{\circ}$ \\ ERGODESIGN USIHC CINAHPA}

Em geral verificou-se um dimensionamento coerente com as proporções do percentil das mãos das crianças, permitindo um manejo leve, ágil e sem constrangimento muscular. A redução da área total do layout, em relação ao formato A4 presente nas pranchas do PECS, não gerou dificuldades no manuseio, e oferece o benefício de ser transportado facilmente pela criança ao longo do dia. Além da portabilidade, o redimensionamento também considerou a adequação da proporção entre figura fundo para otimizar a legibilidade dos pictogramas.

Pensando nos seus diversos usos pela criança, requisitos como a segurança também foram cumpridos, posto que não há arestas salientes, cantos pontiagudos ou rebarbas resultantes do processo produtivo que possam oferecer risco de corte ou perfuração. Além disso, foram respeitadas dimensões técnicas estipuladas pela certificação de brinquedos, como não conter peças inferiores a 30 $\mathrm{mm}$ que possam ser ingeridas pela criança, e a rotulagem de classificação de faixa etária.

Considera-se que o produto atingiu a maioria dos requisitos pretendidos para este trabalho, proporcionando uma nova possibilidade dos pais e colaboradores se relacionarem com o universo da criança. Com este conjunto, é possível facilitar a interação em diferentes níveis, servindo de apoio visual durante a explicação da rotina diária pelos pais e profissionais, e também em atividades simultâneas de identificação, classificação e verbalização dos pictogramas.

Bosa (2002) elucida que é reconhecido que a convivência do autista com outras pessoas desenvolve habilidades, estimula suas capacidades interativas e diminui parte de uma limitação associada ao isolamento social. Devido a esse comprometimento, Nunes (2001) acrescenta que somente " $64 \%$ dos indivíduos não vocais portadores de autismo desenvolverão habilidades comunicativas apenas se forem expostos a formas alternativas de comunicação" (ibid. p.7). Diante do exposto, acentua-se a relevância do presente trabalho, pois além de compreender os aspectos primordiais da comunicação alternativa, propõe uma nova abordagem para auxiliar no ensino das atividades da rotina diária. $16^{\circ}$ Ergodesign - Congresso Internacional de Ergonomia e Usabilidade de Interfaces Humano Tecnológica: Produto, Informações Ambientes Construídos e Transporte

$16^{\circ}$ USIHC - Congresso Internacional de Ergonomia e Usabilidade de Interfaces Humano Computador

CINAHPA | 2017 - Congresso Internacional de Ambientes Hipermídia para Aprendizagem.
As atividades lúdicas são usadas no campo da pedagogia como importante instrumento para o desenvolvimento cognitivo e emocional da criança, pois permite uma livre experimentação e mantém sua concentração. Isso porque a brincadeira para a criança não é apenas uma atividade sem propósito, mas um meio para se comunicar, desenvolver a imaginação e aprender novas habilidades (VYGOTSKY, 1994). Através da brincadeira a criança pode construir um espaço de experimentação que mediará sua transição entre o mundo interno e externo, transpondo as situações vividas na brincadeira para aprendizados futuros, a preparando dessa forma para enfrentar desafios semelhantes.

No caso de crianças com deficiência, apesar das adversidades no campo da coordenação motora, as atividades lúdicas também colaboram para superar suas dificuldades. Por mais trabalhoso e demorado que possa parecer este processo, elas também são incentivadas a encontrar sua autonomia. De acordo com um estudo de Martins e Goés (2013) sobre o brincar de crianças com autismo, durante as brincadeiras as mesmas chegaram a mostrar intenções imaginativas, permitindo-as deslocar-se do seu plano de ações imediata e concreta para atuar no campo dos jogos de papéis.

Apesar de incipiente e pouco desenvolvida, a capacidade de interagir e agir imaginativamente propicia a elevação dos níveis de funcionamento da criança. Isto, pois "a criação de uma situação imaginária pode ser considerada como um meio para desenvolver o pensamento abstrato" (VYGOTSKY, 1994, p.70). Sendo assim, as intenções imaginativas reveladas nas atividades lúdicas se configuram como um elemento de constante ressignificação para a criança, através do qual ela expressa seus desejos que não podem ser realizados imediatamente.

Acrescenta-se ainda que a ênfase lúdica nas atividades que envolvem interações sociais desperta a atenção compartilhada, ativando gradativamente funções superiores tal como a memória, linguagem e imaginação (LOVAAS, 2003). Com isso, a criança começa a perceber o mundo em sua volta, e compreende que para cada 


\section{$16^{\circ}$ \\ ERGODESIGN USIHC CINAHPA}

ação sua há uma reação do ambiente, facilitando comportamentos de empatia.

Partindo do pressuposto de Löbach (2001) no qual o design deve trabalhar para transformar a interface dos produtos considerando seus aspectos estéticos para mediar essa relação, esse trabalho investigou e decompôs os principais elementos do universo infantil para criar a proposta de uma experiência diferenciada (Figura 7), compatível com os diferentes estágios de aprendizado da criança.

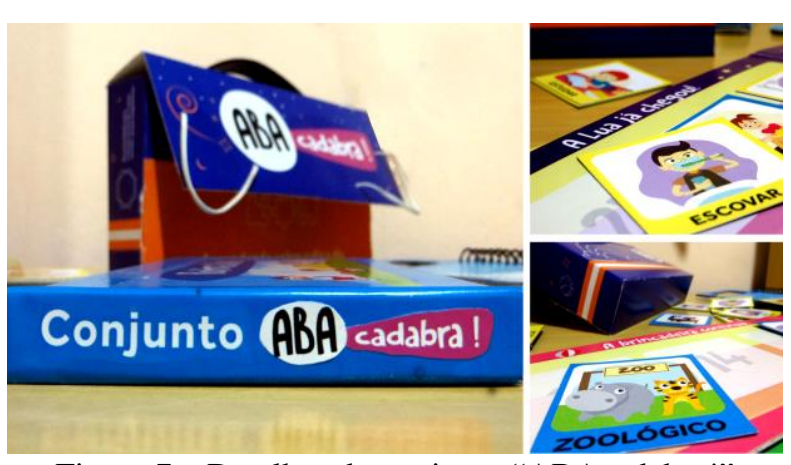

Figura 7 - Detalhes do conjunto "ABAcadabra!"

O conjunto educativo "ABAcadabra!" reproduz a linguagem visual dos livros infantis, possibilitando que as crianças e os pais utilizem no cotidiano, logo desvinculando-se da abordagem técnica evidente na configuração dos conjuntos PECS. Com isso, ao final de um projeto desta amplitude, obteve-se o resultado de um produto lúdico com uma interface estética com alta pregnância da forma (GOMES FILHO, 2006), adequando-se a diferentes rotinas por meio de informações claras e perceptíveis aos usuários. Através dessas diretrizes, a criança pode se sentir incluída no universo infantil, sendo incentivada a utilizar o conjunto sempre que for necessário.

\section{Considerações Finais}

As questões que orientaram o desenvolvimento deste trabalho partiram da premissa que cada criança autista apresenta um potencial próprio para aprender e assim se desenvolver. Sendo assim, foram compreendidos aspectos significativos que favoreçam essa condição, promovendo a participação ativa no processo de modo a sentir-se $16^{\circ}$ Ergodesign - Congresso Internacional de Ergonomia e Usabilidade de Interfaces Humano Tecnológica: Produto, Informações Ambientes Construídos e Transporte

$16^{\circ}$ USIHC - Congresso Internacional de Ergonomia e Usabilidade de Interfaces Humano Computador

CINAHPA | 2017 - Congresso Internacional de Ambientes Hipermídia para Aprendizagem. pertencida. Exposto isso, foi possível considerar outras formas de comunicação para além dos meios convencionais verbais, resultando em melhorias que se adequam a realidade projetual.

Perante a complexidade do espectro autista, ao longo de todo processo foi necessário depreender um período adicional para maturação conceitual do trabalho. Essa fase de imersão incluiu o contato com profissionais da área, e a observação passiva das crianças em situações espontâneas. A partir disso, ficou evidente que a configuração visual das interfaces deve ser diretiva com informações perceptíveis para a criança, sendo que os estímulos devem ser cuidadosamente planejados para melhorar o desempenho durante o processo de aprendizagem.

Os métodos de abordagem do autismo, em sua maioria comportamentais, são aplicados em diversas áreas para garantir que as crianças recebam acompanhamento direcionado às suas potencialidades. Este trabalho identificou e correlacionou os requisitos do projeto com os principais elementos que regem o funcionamento da intervenção $\mathrm{ABA}$, caracterizada pela ação colaborativa entre diferentes profissionais e os pais da criança. Com isso, essa proposta de produto pode ser utilizada em todos os níveis, ampliando, estruturando e modificando a experiência de construção de significados pela criança.

Os resultados esperados visam também incluir uma consciência sobre a prática, discurso e papel social do Design. Desse modo ampliando a visão sobre a abrangência dessa atividade e revelando, sobretudo, seu caráter interdisciplinar e sua relevância na construção de um repertório de produtos baseado na perspectiva da inclusão social.

Diante desses aspectos, o designer deve assumir a responsabilidade de mediar as relações do homem com o meio circundante, apenas na posição de facilitador ou tradutor de suas necessidades, e não como aquele que interfere deliberadamente em sua natureza. Logo, seu papel nada mais é do que conviver, interpretar e apresentar soluções na forma de produtos. 


\section{$16^{\circ}$ \\ ERGODESIGN USIHC CINAHPA}

$16^{\circ}$ Ergodesign - Congresso Internacional de Ergonomia e Usabilidade de Interfaces Humano Tecnológica: Produto, Informações Ambientes Construídos e Transporte

$16^{\circ}$ USIHC - Congresso Internacional de Ergonomia e Usabilidade de Interfaces Humano Computador

CINAHPA | 2017 - Congresso Internacional de Ambientes Hipermídia para Aprendizagem.

\section{Referências Bibliográficas}

BAXTER, M. Projeto de produto: guia prático para o design de novos produtos. 3. ed. São Paulo: Blucher, 2011. $342 \mathrm{p}$.

BONSIEPE, G. Design e Democracia. In: Design, cultura e sociedade. São Paulo: Blucher, 2011. p.17-30.

BOSA, C. A. Autismo: atuais interpretações para antigas observações. In: BAPTISTA, C. R.; BOSA, C. A. Autismo e educação: reflexões e propostas de intervenção. Porto Alegre: Artmed, 2002. p. 2239.

BOSA, C. A. Autismo: Intervenções psicoeducacionais. Revista Brasileira de Psiquiatria, v.28, n. Suppl 1, 2006. p.47-53.

CHRISTENSEN, D; BAIO, J.; BRAUN, K. N.; BILDER, D.; CHARLES, J.; CONSTANTINO, J.; et. al. Prevalence and Characteristics of Autism Spectrum Disorder Among Children Aged 8 Years - Autism and Developmental Disabilities Monitoring Network, 11 Sites, United States, 2012. Morbidity and Mortality Weekly Report, v. 65, n. 3, p. 1-23.

DONDIS, D. A. Sintaxe da linguagem visual. 3. ed. São Paulo: Martins Fontes, 2007. 236 p.

FAGGIANI, R. B. Programa de Tratamento Garoto. Psicologia e Ciência, Terapia ABA, 2011. $25 \mathrm{p}$.

GIL, A. C. Como elaborar projetos de pesquisa. 5. ed. São Paulo: Atlas, 2010. 184 p.

GOMES FILHO, J. Design do objeto: bases conceituais. São Paulo: Escrituras, 2006. 252 p.

GOMES FILHO, J. Gestalt do objeto: sistema de leitura visual da forma. 9. ed. São Paulo:

Escrituras, 2009. 133 p.

IIDA, I. Ergonomia: projeto e produção. São Paulo: E. Blucher, 2003. 465p.
LEBOYER, M. Diagnóstico e definição de autismo infantil precoce. In: Autismo infantil: fatos e modelos. Campinas: Papirus, 1987. p.7-39.

LÖBACH, B. Design industrial: bases para a configuração dos produtos industriais. São Paulo (SP): Edgard Blücher, 2001. 206p.

LOVAAS, I. O. Ensinando Indivíduos com atraso de desenvolvimento: técnicas básicas de intervenção. Austin (TX-USA): Pro-Ed, 2003. $941 \mathrm{p}$.

MANZINI, E. J.; DELIBERATO, D. Recursos para Comunicação Alternativa. Brasília: MEC SEESP, 2004. 52p.

MARTINS, A.D.F.; GÓES, M.C.R. Um estudo sobre o brincar de crianças autistas na perspectiva histórico-cultural. Revista Semestral da Associação Brasileira de Psicologia Escolar e Educacional, SP. Volume 17, Número 1, 2013. p. 25-34.

MIGUEL, C. F.; BRAGA-KENYON, P.B.; KENYON, S.E. Análise Comportamental Aplicada. In: JUNIOR, W.C. Transtornos Invasivos do Desenvolvimento. Brasília: $3^{\circ}$ Milênio, 2005a. p. 148-154.

MIGUEL, C. F.; BRAGA-KENYON, P.B.; KENYON, S.E. Uma introdução ao sistema de comunicação através de troca de figuras (PECS). In: JUNIOR, W.C. Transtornos Invasivos do Desenvolvimento. Brasília: $3^{\circ}$ Milênio, 2005b. p. 179-185.

NORMAN, Donald A. O design do dia-a-dia. Rio de Janeiro: Rocco, 2006. 271 p.

NUNES, D. Efeitos dos procedimentos naturalísticos no processo de aquisição de linguagem através de sistema pictográfico de comunicação em criança autista. 2001. 99 p. Dissertação (Mestrado em Educação) - Faculdade de Educação UERJ, Rio de Janeiro.
Realização:

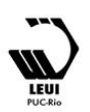




\section{$16^{\circ}$ \\ ERGODESIGN USIHC CINAHPA}

$16^{\circ}$ Ergodesign - Congresso Internacional de Ergonomia e Usabilidade de Interfaces Humano Tecnológica: Produto, Informações Ambientes Construídos e Transporte

$16^{\circ}$ USIHC - Congresso Internacional de Ergonomia e Usabilidade de Interfaces Humano Computador

CINAHPA | 2017 - Congresso Internacional de Ambientes Hipermídia para Aprendizagem.

PEDROSA, I. O universo da cor. Rio de Janeiro: Ed. Senac Nacional, 2003. 153 p.

ROZENFELD, H.; FORCELLINI, F.A.;

AMARAL, D. C.; TOLEDO, J. C.; SILVA, S. L.; ALLIPRANDINI, D. H.; SCALICE, R. H. Gestão de desenvolvimento de produtos: uma referência para a melhoria do processo. São Paulo: Saraiva, 2006. 542 p.

\section{SÁ, T. H. M. O estilo gráfico Flat Design na gestão da interface visual nos dispositivos móveis. 2014. 91 p. Dissertação (Mestrado em Design Gráfico) - Centro de Comunicação e Expressão, UFSC, Florianópolis.}

SILVANO, D. M. S. ABAcadabra! - Um Conjunto Educativo para Crianças com Autismo. 2016. 123 p. Monografia (Graduação em Design de Produto) - Departamento Acadêmico de Metal Mecânica, IFSC, Florianópolis.

SUCHOWIERSKA, M.; RUPIŃSKA, M.; BONDY, A. Picture Exchange Communication System (PECS): A Short "tutorial" for the doctors. Postępy Nauk Medycznych, t. XXVI, nr 1, 2013. p.85-90.

VYGOTSKY, L. S. A formação social da mente: o desenvolvimento dos processos psicológicos superiores. 5 ed. São Paulo: Martins Fontes, 1994. $191 \mathrm{p}$.

VYGOTSKY, L. S. Pensamento e linguagem. 3. ed. São Paulo: Martins Fontes, 2005.135p.

\section{Agradecimentos}

A equipe do CAD/São Carlos e a Dra. Priscila Benitez pelo suporte na pesquisa informacional. 